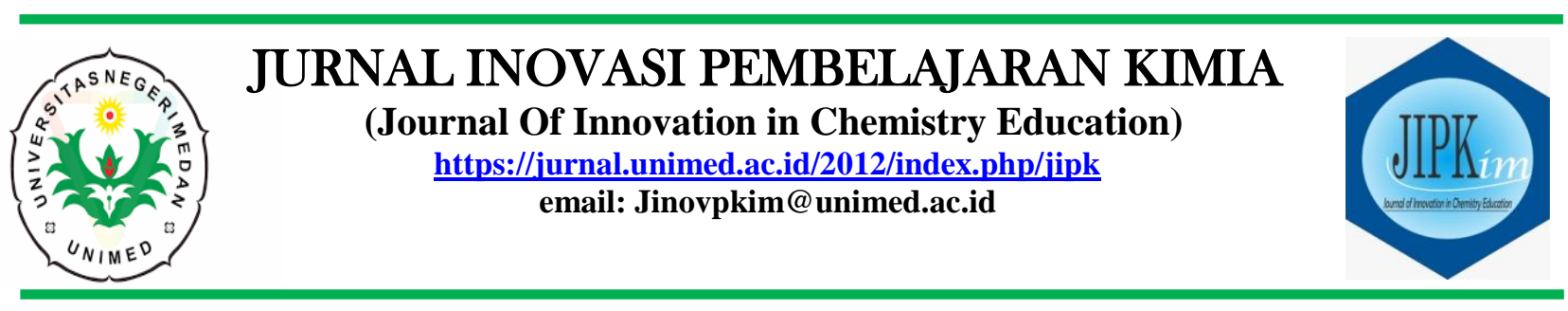

$\begin{array}{ll}\text { Masuk } & : \text { 8 Agustus 2020 } \\ \text { Revisi } & : \text { 15 September 2020 } \\ \text { Diterima } & : \text { 16 September 2020 } \\ \text { Diterbitkan } & : \text { 30 Oktober } 2020 \\ \text { Halaman } & : 51-57\end{array}$

\title{
Peningkatan Motivasi Dan Hasil Belajar Siswa Dengan Menerapkan Peer Tutoring
}

\author{
Purnama Dewi ${ }^{1 *}$ \\ ${ }^{1}$ Program Studi Fisika, Guru SMP Negeri 1 Lintongnihuta, Lintongnihuta \\ *Alamat Korespondensi: helenpurnamadewi@gmail.com
}

\begin{abstract}
This research was conducted with the aim to determine whether the implementation of peer tutoring equipped with handouts can improve student motivation and learning outcomes in class VII odd semester SMP Negeri-1 Lintongnihuta T.A. 2019/2020. This research is a Classroom Action Research. The subjects of this study were 1 class students of class VII, totaling 32 students. The data collection technique uses 20 questions of learning outcomes in the form of multiple choice questions and observation format sheets. The data analysis technique used is qualitative and quantitative data analysis. The results showed that peer tutoring equipped with handouts could improve: (1) student learning motivation, in cycle I it was obtained students with high motivation (6 people), medium motivation ( 8 people) and low motivation (18 people), while in cycle II students with high motivation (20 people), medium motivation (12 people) and no more students who have low motivation; (2) Student learning outcomes in cognitive aspects. In the first cycle, the cognitive aspects of student learning completeness are $25 \%$ with an average value of 55 , while in the second cycle it reaches $100 \%$ with an average value of 89.38 .
\end{abstract}

Keywords: Peer Tutoring, handouts, learning motivation, learning outcomes

\section{PENDAHULUAN}

Kualitas Sumber Daya Manusia (SDM) suatu bangsa secara umum dapat dilihat dari mutu pendidikan bangsa tersebut. Salah satu upaya yang telah dilakukan pemerintah Indonesia dalam meningkatkan mutu pendidikan adalah melakukan pengembangan kurikulum (Mawarni et al., 2014). Dengan demikian, pencapaian standar proses untuk meningkatkan kualitas pendidikan dapat dimulai dari menganalisis setiap komponen yang dapat membentuk dan memengaruhi proses pembelajaran (Sanjaya, 2009). Keberhasilan proses pembelajaran dapat diukur berdasarkan hasil belajar siswa
(Situmorang et al., 2013). Penggunaan alat bantu disadari oleh banyak praktis pendidikan sangat membantu aktitas proses pembelajaran baik di dalam maupun di luar

kelas, terutama membantu peningkatan prestasi belajar siswa. Namun, dalam implementasinya tidak banyak guru yang memanfaatkannya, bahkan penggunaan metode ceramah monoton masih cukup populer di kalangan guru dalam proses pembelajarannya (Munadi, 2008). Kemudian, pembelajaran dilanjutkan dengan diberikan latihan soal. Pada saat memberikan soal guru mengamati bahwa siswa tampak tidak bersemangat dalam mengerjakan soal. Ketika 
ditanya oleh guru mengenai soal yang diberikan, siswa menjawab tidak bisa mengerjakan. Kemudian, soal latihan tersebut dikerjakan guru bersama siswa. Dalam pembelajaran tersebut, terlihat bahwa motivasi belajar yang dimiliki siswa masih kurang (Pratiwi et al., 2018).

Hal ini terlihat dari observasi awal peneliti di SMP Negeri-1 Lintongnihuta ditemukan bahwa hasil belajar IPA siswa di kelas VII-I masih tergolong rendah. Berdasarkan hasil analisis peneliti dari nilai ujian IPA 32 orang siswa diperoleh rata-rata hasil belajar IPA siswa sebesar 37,86. Sedangkan KKM untuk mata pelajaran IPA adalah 65. Bahkan hasil analisis peneliti, dari 32 siswa sebanyak 5 siswa atau $15,63 \%$ memperoleh nilai lebih dari 65 sedangkan 27 siswa atau $84,37 \%$ memperoleh nilai kurang dari 65. Hasil observasi awal peneliti menunjukkan bahwa rata-rata maupun persentase ketuntasan hasil belajar IPA siswa kelas VII-I secara kelas masih sangat rendah.

\section{KAJIAN LITERATUR}

\section{Peer Tutoring}

Setelah

dilakukan

analisis

berdasarkan data penelitian maka diperoleh nilai $t_{\text {hitung }}=2,3380$, dan $t_{\text {tabel }}=1,9949$. Karena nilai $t_{\text {hitung }}>t_{\text {tabel }}$ maka hipotesis yang menyatakan bahwa penggunaan model pembelajaran peer tutoring mampu menghasilkan prestasi belajar yang lebih baik dari pada kelas kontrol yang menggunakan model pembelajaran konvensional dengan menggunakan model pembelajaran langsung (Safitri, 2018). Hasil penelitian menunjukkan siswa yang aktif sesuai kriteria keaktifan belajar pada pra-siklus sebesar $31,25 \%$, pada siklus I siswa yang aktif sesuai kiteria keaktifan belajar mencapai $53,12 \%$, siklus II siswa yang aktif sesuai kriteria keaktifan belajar mencapai 84,38\% (Idris et al., 2017). Hasil penelitian ini menunjukkan bahwa motivasi belajar meningkat sebesar $11,78 \%$ sedangkan Hasil belajar meningkat sebesar $17,89 \%$. Motivasi belajar siswa meningkat dilihat dari aktifitas kelompok dalam berdiskusi, mengerjakan soal latihan, tanya jawab bersama tutor, serta turnamen antar kelompok sehingga dapat disimpulkan bahwa metode peer tutoring dengan Kassitu dapat meningkatkan motivasi dan hasil belajar IPA (Sujatmiani, 2015). Hasil penelitian ini menunjukkan bahwa model pembelajaran peer tutoring dapat memberikan pengaruh terhadap nilai rata-rata hasil belajar siswa. Berdasarkan uji-t pada aspek kognitif diperoleh $t_{\text {hitung }}$ sebesar $=2,9699>t_{\text {tabel }}=$ 1,98 sehingga hipotesis diterima. Hasil analisis secara statistik menunjukkan bahwa nilai rata-rata hasil belajar siswa pada kelas eksperimen lebih besar dari kelas kontrol dimana rata-rata aspek kognitif kelas eksperimen $(80,02)$ lebih tinggi dibandingkan untuk kelas kontrol $(76,86)$ (Sari et al., 2018). Berdasarkan hasil penelitian yang telah dilaksanakan, maka dapat disimpulkan hasil belajar meningkat. Hal tersebut dapat dilihat dari hasil analisis hasil belajar tata hidang menunjukkan bahwa siklus I dan siklus II siswa yang sudah tuntas 23 orang meningkat menjadi 41 orang yang tuntas, siswa yang sudah tuntas dalam belajar meningkat menjadi $100 \%$ yaitu sebanyak 41 orang. Nilai rata- rata yang diperoleh pada siklus I ( $72,56 \%)$, siklus II meningkat menjadi $86.22 \%$. Jadi dengan menggunakan model Tutor Sebaya (peer tutoring) nilai rata-rata hasil belajar siswa meningkat sebesar $13.66 \%$ (Laksemiwati, 2019)

\section{METODE}

Penelitian ini telah dilakukan di SMP Negeri-1 Lintongnihuta Jalan Julianus Sihombing Nomor 4, Sibuntuon Parpea, Kecamatan Lintongnihuta, Kabupaten Humbang Hasundutan, Provinsi Sumatera Utara. Subjek penelitian ini adalah siswa kelas VII-I SMP Negeri- 1 Lintongnihuta semester ganjil T.A. 2019/2020 sebanyak 32 orang siswa. Hasil observasi awal peneliti menemukan bahwa hasil belajar IPA siswa di kelas VII-I masih tergolong rendah. Berdasarkan hasil analisis peneliti dari nilai ujian IPA 32 orang siswa diperoleh rata-rata hasil belajar IPA siswa sebesar 37,86. Sedangkan KKM untuk mata pelajaran IPA adalah 65. 


\section{Desain Penelitian}

Desain Penelitian yang digunakan dalam penelitian ini merupakan Penelitian Tindakan Kelas (PTK) yang mengacu pada penelitian tindakan model Model Taggart dan Kemmis.

Gambar 1. Desain Penelitian

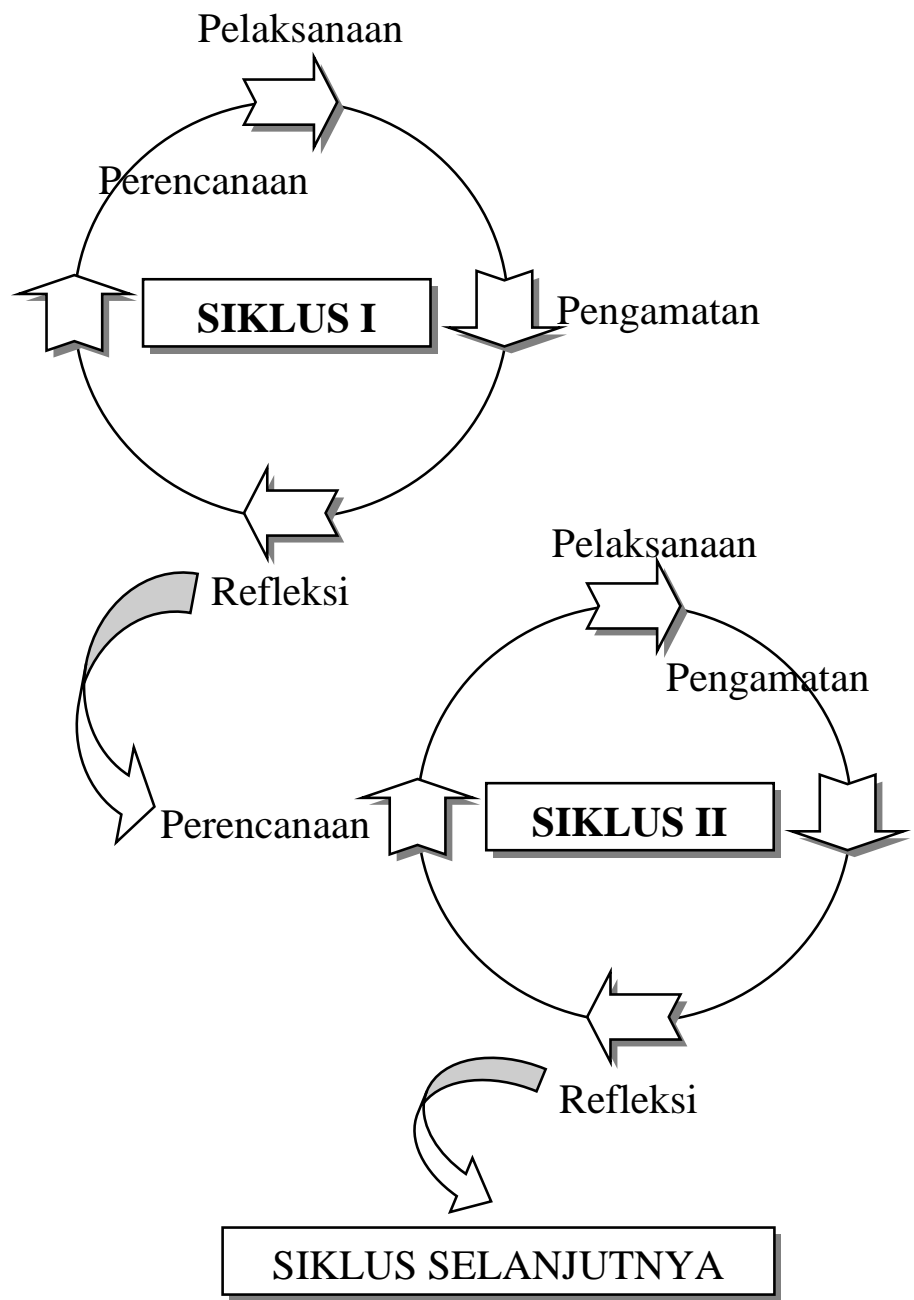

\section{Instrumen Penelitian}

a. Angket

Motivasi belajar siswa diungkap dengan angket yang dikembangkan berdasarkan indikator yang telah ditetapkan.

b. Lembar Observasi pembelajaran

Meliputi lembar observasi motivasi siswa dan lembar observasi pembelajaran guru.

\section{c. Butir Soal}

Berupa soal pre test dan post tes.

\section{Analisis Data}

Data kuantitatif dianalisis dengan analisis deskriptif komparatif dengan melihat perbandingan nilai pre test dan posttes sedangkan data kualitatif dianalisis dengan analisis deskriptif kualitatif dengan mencari poin penting dan informasi tambahan dari hasil observasi.

\section{HASIL DAN PEMBAHASAN}

\section{Siklus 1}

\section{Tindakan}

Pertemuan pertama dilaksanakan pembelajaran sesuai dengan RPP yaitu dengan model pembelajaran peer tutoring, apabila dalam membimbing kelompok tutor masih mengalami kesulitan, tutor bisa bertanya kepada guru.

\section{Pengamatan/ Observasi}

\subsection{Deskripsi Hasil Belajar}

Tabel 1. Nilai Hasil Belajar Siklus I

\begin{tabular}{clcc} 
No & \multicolumn{1}{c}{ Uraian } & Pre test & Post test \\
\hline 1 & Nilai Tertinggi & 45 & 80 \\
2 & Nilai Terendah & 15 & 35 \\
3 & Nilai rata-rata & 30,78 & 55,00 \\
4 & Persentase Ketuntasan & 0 & 25 \\
\hline
\end{tabular}

Gambar 2. Nilai Hasil Belajar Siklus I

\section{Analisis Nilai Hasil Belajar Siklus I}

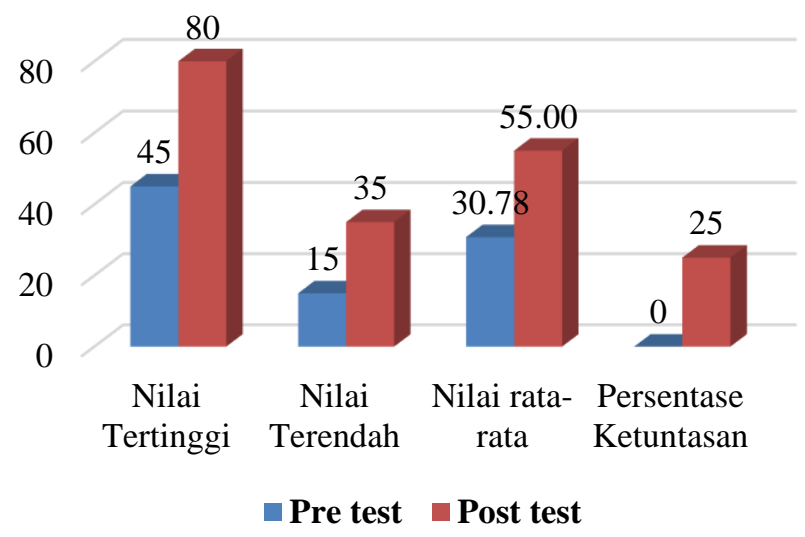

\subsection{Deskripsi Motivasi belajar}

Dari angket didapatkan bahwa motivasi belajar rata- rata dalam satu kelas $25 \%$ (6 orang) termasuk kategori tinggi. 
Tabel 2. Nilai Motivasi Belajar

\begin{tabular}{cccc} 
No & Kategori & Jumlah & Persentase \\
\hline 1 & Tinggi & 6 & 18,75 \\
2 & Sedang & 8 & 25 \\
3 & Rendah & 18 & 56,25 \\
& Jumlah & 32 & 100 \\
\hline
\end{tabular}

Gambar 3. Nilai Motivasi Belajar

\section{Analisis Nilai Motivasi Belajar Siklus I}

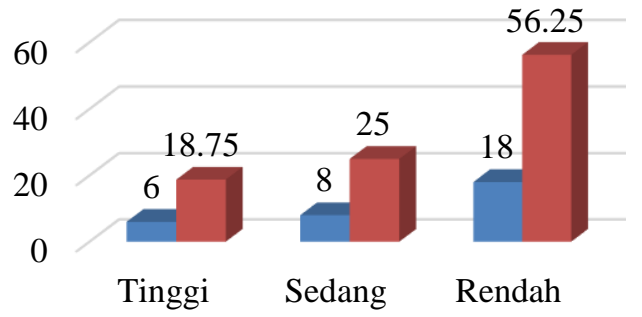

- Jumlah Persentase

\section{Refleksi}

a. Pada saat proses pembelajaran peer tutoring ada 2 tutor yang kurang memperhatikan tapi sudah sibuk mengerjakan soal;

b. Waktu dalam berdiskusi kelompok masih kurang;

c. Guru tidak menjelaskan materi secara klasikal;

d. Pada saat proses pembelajaran peer tutoring tiap kelompok masih kurang mengimplementasikan handout yang sudah diberikan;

e. Tiap kelompok kurang memperhatikan Lembar jawaban yang diberikan sehingga menyulitkan guru dalam mengoreksi lembar jawab siswa;

\section{Siklus 2}

1. Tindakan

Proses pembelajaran dilaksanakan menggunakan model peer tutoring seperti siklus 1 dengan beberapa perbaikan, salah satunya ditambahnya waktu untuk diskusi kelompok, serta pemahaman materi handout.

\section{Pengamatan/ Observasi}

\subsection{Deskripsi Hasil Belajar}

Setelah siklus 2 sudah terdapat peningkatan Hasil belajar dibandingkan siklus 1 .
Tabel 3. Nilai Hasil Belajar Siklus II

\begin{tabular}{clcc}
\hline No & \multicolumn{1}{c}{ Uraian } & $\begin{array}{c}\text { Pre } \\
\text { test }\end{array}$ & $\begin{array}{c}\text { Post } \\
\text { test }\end{array}$ \\
\hline 1 & Nilai Tertinggi & 65 & 100 \\
2 & Nilai Terendah & 45 & 80 \\
3 & Nilai rata-rata & 54,22 & 89,38 \\
4 & Persentase Ketuntasan & 15,63 & 100 \\
\hline
\end{tabular}

Gambar 4. Nilai Hasil Belajar Siklus II

Analisis Nilai Hasil Belajar Siklus II
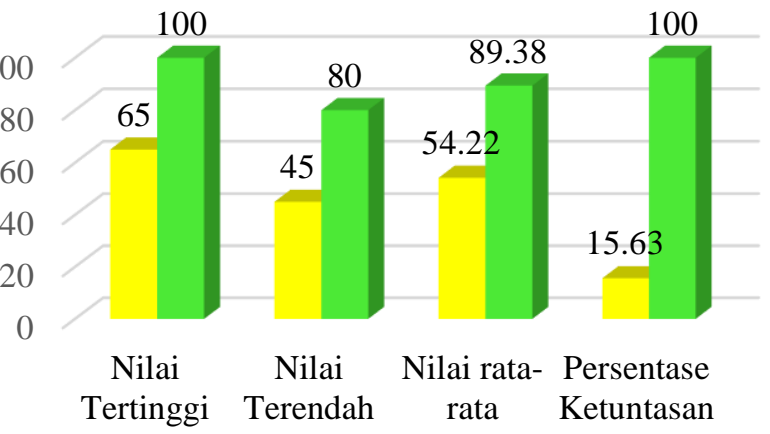

Pre test $\square$ Post test

\subsection{Deskripsi Motivasi belajar}

Dari angket didapatkan bahwa motivasi belajar rata- rata dalam satu kelas $62,5 \%$ (20 orang) termasuk kategori tinggi.

Tabel 4. Nilai Motivasi Belajar

\begin{tabular}{cccc} 
No & Kategori & Jumlah & Persentase \\
\hline 1 & Tinggi & 20 & 62,5 \\
2 & Sedang & 12 & 37,5 \\
3 & Rendah & 0 & 0 \\
& Jumlah & 32 & 100 \\
\hline
\end{tabular}

Gambar 5. Nilai Motivasi Belajar

Analisis Nilai Motivasi Belajar Siklus II

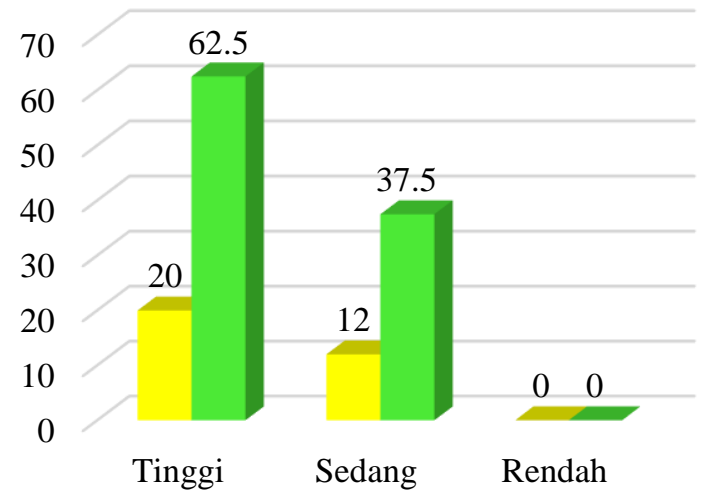

Jumlah Persentase 


\section{Refleksi}

a. Pada saat proses pembelajaran bersama antara tutor dengan guru. Guru menjelaskan kepada semua tutor tiap kelompok untuk memperhatikan handout. Lalu menganalisis dan bertanya jawab serta berdiskusi bagaimana cara penyelesaian soal yang tepat;

b. Waktu yang digunakan dalam berdiskusi kelompok sudah cukup sehingga semua siswa memiliki waktu yang cukup untuk menguasai materi atau soal yang harus dipelajari dalam kelompok;

c. Guru terlebih dahulu memberikan materi secara klasikal lalu mendalami materi menggunakan handout sehingga menambah pemahaman siswa;

d. Pada saat diskusi antar kelompok siswa, merka sudah lebih teratur karena kelompok siswa memulai setiap soal bersama- sama;

e. Lembar jawaban diskusi antar kelompok dijadikan satu untuk setiap kelompok sehingga memudahkan guru dalam mengoreksi lembar jawab turnamen;

f. Pada meja kelompok terdapat nama kelompok sehingga tidak ada kelompok yang salah tempat

\section{DISKUSI}

Tabel 5. Analisis Nilai Hasil Belajar

\begin{tabular}{cccccc}
\hline No & Siklus & $\begin{array}{c}\text { Nilai } \\
\text { Pre } \\
\text { test }\end{array}$ & $\begin{array}{c}\text { Persen } \\
\text { Ketuntasan }\end{array}$ & $\begin{array}{c}\text { Nilai } \\
\text { Pos } \\
\text { test }\end{array}$ & $\begin{array}{c}\text { Persen } \\
\text { Ketuntasan }\end{array}$ \\
\hline 1 & Siklus I & 30,78 & 0,00 & 55,00 & 25 \\
2 & Siklus II & 54,22 & 15,63 & 89,38 & 100 \\
\hline
\end{tabular}

Gambar 6. Analisis Nilai Hasil Belajar

\section{Analisis Hasil Belajar}

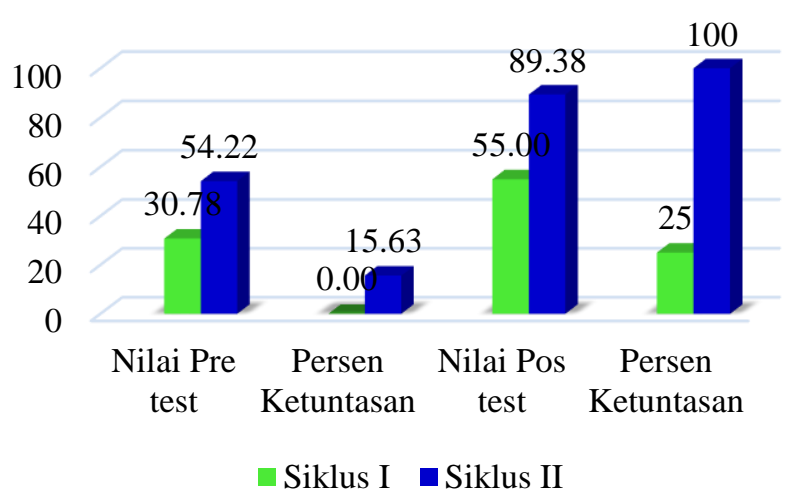

Tabel 6. Analisis Motivasi Belajar

\begin{tabular}{ccccc}
\hline & & \multicolumn{3}{c}{ Persentase Motivasi } \\
\cline { 3 - 5 } No & Siklus & Tinggi & Sedang & Rendah \\
& & & & \\
\hline 1 & Siklus I & 18,75 & 25 & 56,25 \\
2 & Siklus II & 62,5 & 37,5 & 0 \\
\hline
\end{tabular}

Gambar 7. Analisis Motivasi Belajar

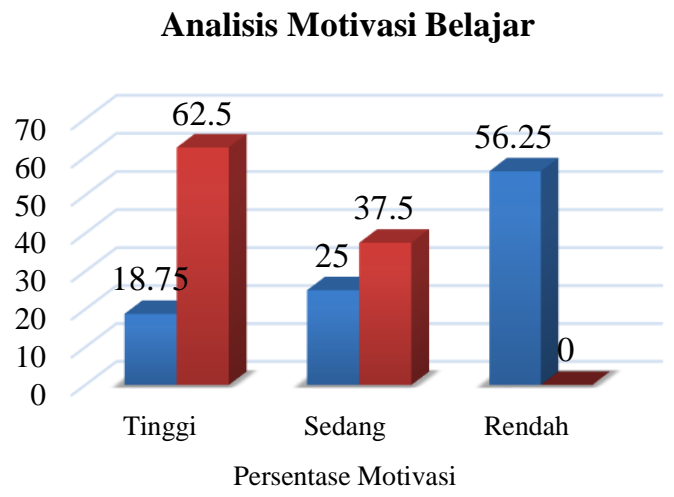

-Siklus I Siklus II

Tabel 7. Analisis Pra Siklus, Siklus I dan II

\begin{tabular}{clccc}
\hline No & Siklus & Rata-rata & $\begin{array}{c}\text { Persen } \\
\text { Ketuntasan }\end{array}$ & Frekuensi \\
\hline 1 & Pra & 30,78 & 0 & 0 \\
2 & Siklus I & 55 & 25 & 8 \\
3 & Siklus II & 89,38 & 100 & 32 \\
\hline
\end{tabular}

Gambar 8. Analisis Hasil Belajar

Analisis Hasil Belajar Pra, Siklus I dan Siklus II

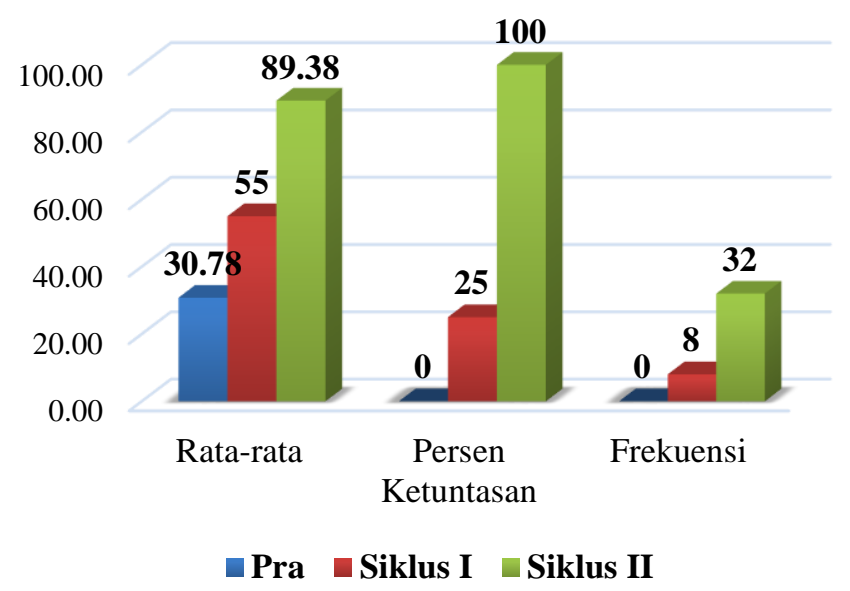

Berdasarkan dari tabel dan gambar di atas Dari histogram tersebut dapat diamati bahwa dari pra siklus, siklus I dan ke siklus II terdapat peningkatan motivasi dan hasil belajar siswa. 


\section{KESIMPULAN}

Berdasarkan uraian di atas, dapat ditarik kesimpulan bahwa model pembelajaran Peer Tutoring dengan handout dapat meningkatkan motivasi dan hasil belajar IPA di kelas VII-I SMP Negeri- 1 Lintongnihuta. Peningkatan hasil belajar IPA siswa dapat dilihat dari rata-rata nilai dan ketuntasan belajar siswa secara klasikal: (1) Dari hasil pretes diperoleh rata-rata nilai sebesar 30,78 atau tergolong rendah dengan persetase ketuntasan secara klasikal sebesar 0\%; (2) Pada siklus I, hasil belajar siswa meningkat dengan rata-rata nilai sebesar 55 dan jumlah siswa yang dinyatakan tuntas sebanyak 8 siswa atau 25\%. Hal ini berarti secara klasikal para siswa masih dinyatakan belum mencapai ketuntasan dalam belajar karena masih kurang dari $85 \%$, sehingga masih perlu dilakukan tindakan siklus II. Sedangkan untuk motivasi belajar pada siklus I. Siswa dengan motivasi tinggi (6 orang), motivasi sedang (8 orang) dan motivasi rendah (18 orang), sehingga masih perlu dilakukan tindakan siklus II; (3) Setelah dilakukan perbaikan pembelajaran pada siklus II, dari hasil postes rata-rata hasil belajar siswa meningkat menjadi sebesar 89,38 dan jumlah siswa yang tuntas sebanyak 32 siswa atau $100 \%$ dan secara klasikal para siswa dinyatakan telah berhasil mencapai ketuntasan dalam belajar. Sedangkan untuk motivasi belajar pada siklus II. Siswa dengan motivasi tinggi (20 orang), motivasi sedang (12 orang) dan tidak ada lagi siswa yang memiliki motivasi rendah.

\section{DAFTAR PUSTAKA}

Idris, R. P., Widiastuti, I., \& Wardani, N. S. (2017). Penerapan Pembelajaran Model Tutor Sebaya ( Peer Tutoring ) Untuk Meningkatkan Keaktifan Dan Prestasi Belajar Siswa Dalam Mata Pelajaran Mekanika Teknik Kelas X. Seminar Nasional Pendidikan Vokasi $\mathrm{Ke}$ 2, 2, 356-361.

Laksemiwati, N. L. A. (2019). Implementasi Model Pembelajaran Tutor Sebaya (Peer Tutoring) untuk Meningkatkan
Aktivitas dan Hasil Belajar Tata Hidang. Journal of Education Action Research, 3(1), 31-37. https://doi.org/10.23887/jear.v3i1.170 84.

Mawarni, E., Mulyani, B., \& Yamtinah, S. (2014). Penerapan Peer Tutoring Dilengkapi Animasi Macromedia Flash Dan Handout Untuk Meningkatkan Motivasi Berprestasi Dan Prestasi Belajar Siswa Kelas XI IPA 4 SMAN 6 Surakarta Tahun Pelajaran 2013/2014 Pada Materi Kelarutan Dan Hasil Kali Kelarutan. Jurnal Pendidikan Kimia Universitas Sebelas Maret, 4(1), 29-37.

Munadi, Y., (2008), Media Pembelajaran, Penerbit Gaung Persada Press, Jakarta.

Pratiwi, B. L., Kuswardi, Y., \& Fitriana, L. (2018). Upaya Peningkatan Motivasi Belajar Siswa Melalui Model Pembelajaran Problem Based Learning Dengan Strategi Motivasi ARCS (Attention, Relevance, Confidence, Satisfaction) Pada Siswa Kelas XI IPA 2 SMA Negeri 1 Petanahan Tahun Pelajaran 2017/2018 Bibit. Jurnal Pendidikan Matematika Dan Matematika (JPMM) Solusi, 2(2), 161-169.

Safitri, D. N. (2018). Eksperimentasi Model Pembelajaran Peer-Tutoring Terhadap Prestasi Belajar Mahasiswa Program Studi Pendidikan Matematika. Jurnal Pendidikan Edutama, 5(2), 31-36. https://doi.org/10.30734/jpe.v5i2.185.

Sanjaya, W., (2009), Strategi Pembelajaran Berorientasi Standar Proses Pendidikan, Penerbit Kencana, Jakarta.

Sari, M. P., Yelianti, U., \& Harlis. (2018). Pengaruh Model Pembelajaran Peer Tutoring Terhadap Hasil Belajar Siswa Pada Materi Plantae Di Kelas X Sma N 10 Kota Jambi. Biodik, 3(1), 1-8. 
https://doi.org/10.22437/bio.v3i1.487

1.

Situmorang, G.I., Suyanti, D.R., dan Mahmud., (2013), Pengaruh Model Pembelajaran Inkuiri Dengan Menggunakan Media Microsoft Frontpage Dan Aktivitas Belajar Terhadap Hasil Belajar IPA Siswa Pada Pokok Bahasan Zat Aditif Kelas VIII SMP, Jurnal Pendidikan Kimia Pascasarjana Unimed, 5(3),139-147.

Sujatmiani. (2015). Penggunaan Metode Peer Tutoring dengan Kassitu untuk Meningkatkan Motivasi dan Hasil Belajar IPA Fisika. Jurnal Riset Dan Kajian Pendidikan Fisika, 2(2), 46.

https://doi.org/10.12928/jrkpf.v2i2.3 248. 